\title{
eNOS, metabolic syndrome and cardiovascular disease
}

\author{
Paul L. Huang \\ Cardiovascular Research Center and Cardiology Division, Massachusetts General Hospital and \\ Harvard Medical School, Boston, MA 02114, USA
}

\begin{abstract}
Large epidemiologic studies have established that diabetes, hyperlipidemia and obesity all increase the risk for cardiovascular disease. However, the precise mechanisms by which these metabolic disorders increase the propensity to develop atherosclerosis are not known. Recently, the concept of the metabolic syndrome - a constellation of conditions including obesity, hypertension, hyperlipidemia and insulin resistance - has received much attention. Studies on the metabolic syndrome might enable a better understanding of the underlying biological mechanisms that lead to cardiovascular disease. This review focuses on endothelial nitric oxide synthase and summarizes evidence that a reduction in the bioavailability of endothelium-derived nitric oxide serves as a key link between metabolic disorders and cardiovascular risk.
\end{abstract}

\section{Why is metabolic syndrome important to cardiovascular disease?}

The metabolic syndrome is a clustering of known cardiovascular risk factors, including obesity, hyperglycemia, dyslipidemia and hypertension. Although it had been known for many years that each of the component features of metabolic syndrome is also a cardiovascular risk factor, this concept received renewed interest with the description of 'Syndrome X' by Gerald Reaven at the 1988 Banting Lecture of the American Diabetes Association [1]. The concept of the metabolic syndrome has several important consequences. First, when applied to clinical settings, it identifies a group of patients at increased risk of developing type 2 diabetes (T2D) and cardiovascular disease (CVD). Depending on the definition used, people with metabolic syndrome have up to a fivefold higher risk of T2D and a two-to-threefold higher risk of atherosclerotic CVD than those without [2,3]. Second, the fact that the individual component features cluster together provides information about their interrelationships and shared pathophysiologic mechanisms. An active area of investigation is the molecular mechanisms by which cardiovascular disease risk is increased by metabolic syndrome and whether new treatment approaches can be developed to target these mechanisms. This review explores the relationships between metabolic syndrome, endothelial dysfunction and endothelial nitric oxide synthase (eNOS).

\section{The concept of the metabolic syndrome}

The National Cholesterol Education Program (NCEP) Adult Treatment Panel III (ATPIII)'s definition of metabolic syndrome was developed in 2001 [4] and revised in 2005 [3] (Table 1). This definition states that metabolic syndrome is present if any three of five criteria are met: obesity (waist circumference of more than 40 inches for men or 35 inches for women), hypertension (over 135 systolic or over 85 diastolic), fasting hypertriglyceridemia (over 150 $\mathrm{mg} / \mathrm{dl}$ ), low high-density lipoprotein (HDL) cholesterol (less than 40 in men or 50 in women) and fasting hyperglycemia (currently, glucose over $100 \mathrm{mg} / \mathrm{dl}$ ). Being on medication for these 
conditions (for example, anti-hypertensives or fibrates) also meets these criteria. These criteria were selected because they are readily apparent from physical examination and/or commonly obtained laboratory tests. Thus, the NCEP ATPIII criteria are easily applied in patient care settings and large epidemiologic studies. Two additional features thought to play a part in the pathophysiology of the metabolic syndrome are hypercoagulability and systemic inflammation $[5,6]$.

The NCEP ATPIII criteria are similar to the other major definitions of metabolic syndrome (Table 1), including those from the World Health Organization (WHO) [7], the European Group for the Study of Insulin Resistance (EGIR) [8] and the International Diabetes Federation (IDF) [9]. Common features of all of these definitions include glucose intolerance or insulin resistance, obesity, hypertension and dyslipidemia. However, several important points deserve mention [10,11]. First, the specific absolute criteria are particular for each population; standards for waist circumference, for example, are different for diverse ethnic groups and nationalities. Second, the various definitions differ by how they are structured. The NCEP ATPIII definition requires any three of the five defining characteristics, but no single one is absolutely required. By contrast, the WHO and EGIR definitions require the presence of diabetes, impaired glucose tolerance or insulin resistance for the diagnosis of metabolic syndrome, and the IDF definition requires central obesity. These differences probably reflect the components each organization considers as the primary and central causes of the overall clustering of the component risks. Third, the more complicated definitions might involve tests and measurements not routinely used in patient care, such as euglycemic clamp measurements, limiting their widespread application. Finally, the utility of the syndrome depends on whether its purpose is to identify patients at increased risk of T2D or coronary disease.

Despite these differences in definition and controversy about the utility of the concept [1013], the clustering of defining characteristics in metabolic syndrome indicates that these individual characteristics - central obesity, insulin resistance, hypertension and dyslipidemia - are not independent of one another and are probably interrelated in many complex ways. One framework holds that obesity, particularly visceral or central obesity, is the primary abnormality [7,8]. Visceral obesity might lead to insulin resistance and T2D, and adipokines secreted by visceral fat can have vascular consequences that increase CVD risk [14]. Another framework holds that insulin resistance is the primary abnormality and results in metabolic derangements that lead to hypertension, dyslipidemia and an increased risk of CVD [9]. The connections between either obesity or insulin resistance and the actual mechanisms of increased atherogenesis involve effects on the vascular endothelium.

\section{Endothelial dysfunction and eNOS}

The endothelium comprises the inner lining of blood vessels. In contrast to the earlier viewpoint that the function of the endothelial lining of vessels is to serve as a mechanical barrier, we now know that the endothelium also senses and responds to physiologic and pathologic stimuli $[15,16]$. It produces vasoactive substances, including nitric oxide (NO), prostacyclin and endothelins. The expression of surface cell adhesion molecules governs interactions with circulating cells; these are leukocytes and monocytes, affecting inflammation, and platelets, ultimately affecting thrombosis. The endothelium also modulates the proliferation and injury response of the vascular smooth muscle layer, which contributes to neointima formation during the development of atherosclerotic plaques. These roles of the endothelium parallel current concepts about the pathogenesis of atherogenesis [17,18], which involve abnormalities in vascular signaling, oxidative stress, inflammatory cells and thrombosis. Normal endothelial function protects against these processes, and endothelial dysfunction is central to the pathogenesis of atherosclerotic lesion development. 
NO is a gas produced by nitric oxide synthase (NOS) enzymes $[19,20]$. There are three major isoforms of NOS, encoded by separate genes on separate chromosomes (Table 2): neuronal NOS (nNOS), or type 1 NOS; inducible NOS (iNOS), or type 2 NOS; and eNOS, or type 3 NOS. The essential role of $\mathrm{NO}$ as the elusive endothelium-derived relaxing factor (EDRF) was the topic of the 1998 Nobel Prize in Physiology or Medicine [21,22]. eNOS-derived NO serves important functions, including regulation of vascular tone and regional blood flow, suppression of vascular smooth muscle cell proliferation, modulation of leukocyte-endothelial interactions and modulation of thrombosis. These functions are confirmed by the phenotypes of eNOSknockout mice. eNOS gene deficiency results in hypertension [23], increased vascular smooth muscle cell proliferation in response to vessel injury [24], increased leukocyte-endothelial interactions [25], hypercoagulability [26] and increased diet-induced atherosclerosis [27,28].

A common feature of many cardiovascular risk factors (including hypertension, diabetes, insulin resistance, obesity and hyperlipidemia) is endothelial dysfunction. Because the endothelium normally protects against the processes involved in atherogenesis - namely, smooth muscle cell proliferation, inflammation and thrombosis - endothelial dysfunction is an important final common pathway by which these risk factors increase atherosclerosis.

Endothelial dysfunction, broadly defined, occurs when the endothelium fails to serve its normal physiologic and protective mechanisms [29,30]. This might occur because the endothelium is damaged or missing, as in the case of denuded endothelium in coronary arteries subjected to angioplasty or percutaneous intervention. It might also occur as a result of metabolic toxins, such as free fatty acids (FFAs) and inflammatory cytokines, including IL- 6 and TNF- $\alpha$. Hyperglycemia, advanced glycation products and other metabolic abnormalities might alter endothelial intracellular signaling pathways, such as the PI3K-Akt pathway. Finally, reactive oxygen species (ROS), particularly superoxide, might scavenge vascular $\mathrm{NO}$ and prevent it from inducing vascular smooth muscle relaxation [31-33].

Although it is difficult to assess all of the functions of the endothelium, one commonly used surrogate endpoint for endothelial dysfunction is whether physiologic vasodilator responses are intact $[29,30]$. Vascular dilation to mediators such as acetylcholine or increased blood flow depends on NO produced by the endothelium [15,34-36]. In the catheterization laboratory, this can be measured by monitoring the effect of intracoronary acetylcholine infusion. In the clinical setting, it is reflected by flow-mediated dilation (FMD), measured by ultrasound detection of the response of the brachial artery diameter to reflow after a period of vascular occlusion by a blood pressure cuff [37]. Although each method measures responses in different vascular beds, FMD correlates with the catheterization laboratory measurements of coronary circulation responses [38]. Furthermore, FMD predicts future cardiovascular events [39]. Thus, FMD is a commonly used method to assess endothelial function, and impaired FMD is taken to reflect endothelial dysfunction. Overall, endothelial dysfunction is an important pathophysiologic link between atherogenesis and many known cardiovascular risk factors such as hypertension, obesity, diabetes and dyslipidemia.

There are multiple mechanisms for endothelial dysfunction [20,40], as shown in Figure 1. A common feature of endothelial dysfunction is reduced bioavailability of NO in the vasculature. Possible mechanisms for impaired NO availability include a reduction in eNOS mRNA or protein expression levels [41]. However, studies in animal models and humans suggest that diabetes and atherosclerosis are not necessarily associated with a decrease in the amount of total eNOS [42,43]. L-arginine, the substrate for eNOS, can also be a limiting factor in tissues [44]. An endogenous competitive inhibitor, asymmetric dimethylarginine (ADMA), might reduce endothelial NO production even in the presence of adequate L-arginine levels [44]. This is the basis for recommendations for arginine supplementation to enhance eNOS-derived NO production. However, under certain conditions, increased eNOS enzymatic activity in the setting of cofactor deficiency might be more harmful than beneficial [45]. eNOS requires 
enzymatic cofactors, including flavin adenine dinucleotide, flavin mononucleotide, nicotine adenine dinucleotide hydrogen phosphate (NADPH), and tetrahydrobiopterin $\left(\mathrm{BH}_{4}\right) . \mathrm{BH}_{4}$, the synthesis of which is rate limited by guanosine 5 ' triphosphate cyclohydrolase, is particularly important because in its absence, electron transport through eNOS can become 'uncoupled', resulting in superoxide anion generation [46]. For full enzymatic activity, eNOS requires proper dimerization and intracellular localization to caveolae, mediated in part by proteinprotein interactions with caveolin and heat shock protein 90 (hsp90) [15,47]. eNOS is phosphorylated at serine 1177 (S1177) by Akt kinase and other kinases [48-51], discussed in detail below. Finally, NO produced by eNOS might be rapidly inactivated by reaction with superoxide $\left(\mathrm{O}_{2}-\right)$ to form peroxynitrite anion $\left(\mathrm{OONO}^{-}\right)$[52]. Superoxide can be formed by $\mathrm{NAD}(\mathrm{P}) \mathrm{H}$ oxidase [53] or by uncoupled eNOS [46]. Thus, there are multiple mechanisms that can lead to endothelial dysfunction. They are not mutually exclusive, and multiple mechanisms can operate simultaneously. However, the common feature is a reduction in the amount of bioavailable NO, which normally serves to protect the vessel from the molecular events that lead to atherosclerosis.

\section{Insulin signaling}

Normal insulin signaling results in glucose uptake by skeletal muscle and fat, suppression of hepatic gluconeogenesis, and vasodilation from increased eNOS enzymatic activity $[32,33]$. These effects are mediated by insulin binding to the insulin receptor, a ligand-activated tyrosine kinase receptor. Binding and activation of the insulin receptor results in tyrosine phosphorylation of insulin receptor substrates (IRS) and Shc, resulting in the activation of two parallel pathways: the PI3 Kinase (PI3K)-Akt pathway and the Ras/Raf/MAP kinase pathway (Figure 2). Phosphorylation of IRS-1 leads to activation of the PI3K-Akt pathway. Akt kinase phosphorylates eNOS at S1177 and activates it, as discussed below. In skeletal muscles and adipose tissue, Akt stimulates the expression of the glucose transporter GLUT4, resulting in glucose uptake. Phosphorylation of Shc leads to activation of the Ras/Raf/MAP kinase pathways, resulting in mitogenic effects, as well as increased endothelin 1 (ET-1) expression $[54,55]$.

Insulin resistance is defined as decreased sensitivity of peripheral tissues to insulin effects $[32,33]$. Insulin resistance alters the balance between the two pathways to downstream insulin signaling. Specifically, the PI3K-Akt pathway is altered in insulin resistance [56,57]. This results in diminished eNOS activity, less NO generation and diminished insulin-mediated vasodilation [32]. In the peripheral tissues, insulin resistance leads to decreased glucose uptake in skeletal muscle and adipose tissues because of downregulation of GLUT4 translocation [54,55]. By contrast, the Ras/Raf/MAP kinase pathway is generally preserved in insulin resistance [32]. Thus, unopposed ET-1 production and mitogenic effects persist and contribute to the vascular effects of insulin resistance.

The relationship between endothelial dysfunction and insulin resistance is complex, as shown in Figure 3. Metabolic abnormalities seen in obesity, diabetes and metabolic syndrome include insulin resistance and visceral adiposity. Both might cause endothelial dysfunction and, as a result, lead to development of atherosclerosis [33,58,59]. Conversely, endothelial dysfunction, specifically deficiency of endothelial NO, might lead to metabolic abnormalities, including insulin resistance $[31,60]$. In addition, insulin resistance can cause atherogenic dyslipidemia and contribute to visceral adiposity [32].

\section{Oxidative stress and eNOS}

Under conditions of oxidative stress, $\mathrm{O}_{2}-$ production increases. $\mathrm{O}_{2}-$ reacts with $\mathrm{NO}$ to form OONO- in an extremely rapid reaction that is essentially diffusion limited [52]. Thus, $\mathrm{O}_{2}{ }^{-}$ scavenges $\mathrm{NO}$ and renders it unavailable to mediate its physiologic functions, including 
binding to soluble guanylate cyclase to stimulate vasodilation. In addition, OONO- can cause direct oxidative damage, as well as tyrosine phosphorylation of endogenous proteins, affecting their function [61].

Because uncoupled eNOS not only generates NO but also generates $\mathrm{O}_{2}^{-}$, increasing eNOS transcription, translation or activity does not guarantee improved endothelial function [47]. In fact, as a potential source of $\mathrm{O}_{2}^{-}$, uncoupled eNOS might actually worsen the situation as compared with enzymatically inactive or absent eNOS. This is an important limitation to transgenic or gene therapy approaches to increase vascular eNOS expression.

\section{Effects on eNOS S1177 phosphorylation}

eNOS is phosphorylated at various serine and threonine residues [20,62]. Of these potential phosphorylation sites, S1177 seems to be a crucial regulator of its enzymatic activity. S1177 phosphorylation results in increased electron flux through the reductase domain and reduced calmodulin dissociation. As a result, eNOS becomes more active and produces more NO, even at resting levels of intracellular calcium [63].

There are several lines of evidence that indicate that eNOS S1177 phosphorylation is crucial to the link between metabolism and vascular dysfunction. First, animal models of diabetes, hypercholesterolemia and atherosclerosis, such as $d b / d b$ mice and apoE-knockout mice, show diminished eNOS phosphorylation [64,65]. Second, estrogens [66], statins [67], and peroxisome proliferator activated receptors PPAR $\alpha$ and PPAR $\gamma$ agonists $[68,69]$ increase eNOS S1177 phosphorylation. Third, vasculoprotective signaling molecules such as insulin, IGF-1, vascular endothelial growth factor (VEGF), adiponectin and leptin [49,51,70-72] all increase eNOS S1177 phosphorylation. Fourth, laminar shear stress and flow increase S1177 phosphorylation $[48,50,73]$. Thus, eNOS S1177 phosphorylation seems to be a crucial step in regulating eNOS activity and an important target for intervention to treat endothelial dysfunction [40].

In addition to Akt kinase [48-51], eNOS S1177 is known to be phosphorylated by several other kinases, including AMP kinase [70], protein kinase A (PKA) and protein kinase G (PKG) [74], and calmodulin-dependent kinase II (CaMKII) [75]. Shear stress, VEGF, insulin, estrogens, statins and leptin stimulate eNOS S1177 phosphorylation by Akt kinase activation $[66,67,72,76]$. By contrast, adiponectin and resistin modulate $\$ 1177$ phosphorylation through AMP kinase [70,77]. That diverse signaling pathways affect multiple kinases that converge to modulate eNOS activity by S1177 phosphorylation suggests that this might be a common integration point that underlies endothelial dysfunction from various causes (Figure 4).

Insulin resistance causes endothelial dysfunction by decreasing Akt kinase activity, resulting in diminished eNOS phosphorylation and activity. Because eNOS S1177 phosphorylation is required for the hemodynamic actions of insulin, its lack of phosphorylation results in diminished blood flow to skeletal muscle, creating a vicious cycle [32]. In addition, insulinmediated ET-1 expression and mitogenic effects are not affected by insulin resistance [32], further contributing to endothelial dysfunction.

\section{Effects of adipokines and FFA from visceral fat}

The primary metabolic abnormalities seen in metabolic syndrome lead to the accumulation of visceral fat. White adipose tissue is known to play a part not only in energy storage but also in the production of factors that affect other tissues, including the vasculature $[14,78]$. These factors include resistin, IL-6 and TNF- $\alpha$, which decrease eNOS S1177 phosphorylation, resulting in diminished eNOS activity and less NO generation. In addition to blocking IRS-1 activation, TNF- $\alpha$ directly activates NADPH oxidase, increasing $\mathrm{O}_{2}{ }^{-}$generation, and 
stimulates lipolysis, resulting in more FFA release [79]. In visceral fat, leptin resistance also increases the generation of ROS [80]. In contrast to these other adipokines, adiponectin is protective against CVD [14,77], in that it stimulates eNOS S1177 phosphorylation by AMP kinase to enhance physiologic endothelial function and NO production. Interestingly, adiponectin levels are decreased in T2D, obesity and IR [58,59]. FFA production from visceral fat is increased under conditions of insulin resistance. FFA contributes to endothelial dysfunction by a combination of diminished PI3K-Akt signaling, increased ROS and increased ET-1 production $[32,58,59]$.

\section{Endothelial dysfunction causes insulin resistance}

In addition to the effects of obesity, insulin resistance and metabolic abnormalities on eNOS and endothelial function, eNOS itself is required for intact insulin signaling [54,71,81]. Insulinmediated increases in eNOS activity and NO production lead to increased blood flow and functional capillary recruitment to peripheral tissues [32]. This results in increased delivery of insulin and glucose to skeletal muscle and fat, which contributes to insulin-mediated glucose uptake. Thus, when endothelial dysfunction occurs and vascular redistribution effects of insulin are blunted, there is a vicious cycle that results in further reduction in the metabolic effects of insulin in peripheral tissues owing to decreased delivery of glucose and insulin to the tissues.

\section{eNOS and mitochondrial function}

An additional important link between eNOS and insulin resistance is the essential role of eNOSderived NO in mitochondrial biogenesis [82-85]. In many different cell types, including white and brown adipocytes, $\mathrm{NO}$ donors or the exogenous expression of eNOS stimulates mitochondrial biogenesis through a cyclic GMP-dependent mechanism [86]. A reduction in bioavailability of eNOS-derived NO might result in abnormalities in energy homeostasis, resulting in insufficient generation of energy from stored fat in white adipose tissue and insufficient generation of heat (thermogenesis) from brown adipose tissue. Both of these effects would lead to increased fat storage. Systemic treatment of mice with pharmacologic inhibitors of eNOS results in defective adaptive thermogenesis. Furthermore, eNOS-knockout mice fail to respond to cold exposure by thermogenesis, and their brown adipose tissue development and function are defective [86]. eNOS-knockout mice also fail to show mitochondrial biogenesis in response to exercise or caloric restriction [87]. Taken together, these results show that reduction in bioavailable eNOS-derived NO might lead to abnormalities in energy homeostasis and adipocyte differentiation that increase the risk for metabolic syndrome. In fact, eNOS-knockout mice have been considered to be an important mouse model for the metabolic syndrome [83] because they combine many of its defining features, including hypertension, endothelial dysfunction, insulin resistance and obesity.

\section{Directions for future research}

Insulin resistance and visceral adiposity, two key features of the metabolic syndrome, contribute to endothelial dysfunction by reducing endothelial NO bioavailability. The mechanisms for these effects include alterations in PI3K-Akt signaling, resulting in diminished eNOS phosphorylation at S1177, direct effects of adipokines and FFA on endothelial cell function, and generation of ROS and scavenging of NO (Figure 3). In addition, endothelial dysfunction itself affects insulin signaling and perpetuates a vicious cycle whereby reduction in tissue perfusion and delivery of glucose and insulin causes further insulin resistance, leading to continued effects on endothelial function. Endothelial dysfunction also leads to defects in mitochondrial biogenesis, which contribute to insulin resistance and abnormal energy homeostasis. 
An important unanswered question is whether intervention at any of these interrelated points - insulin resistance, visceral adiposity or endothelial dysfunction - can effectively break this cycle. For example, can interventions designed to increase insulin sensitivity at the peripheral tissue level translate into decreased adiposity or improved endothelial function? Can interventions designed specifically to improve endothelial function improve insulin sensitivity? Can small molecules that increase eNOS S1177 phosphorylation reverse endothelial dysfunction associated with diabetes, obesity or metabolic syndrome? Such small molecules might act on the kinases that phosphorylate S1177 (Akt, AMPK, PKA, PKG and CaMKII) or the phosphatases that mediate its dephosphorylation, which have not yet been well characterized. In this regard, genetically altered mice carrying phosphomimetic or unphosphorylatable mutations at eNOS S1177 might serve as useful tools to establish proof of principle of eNOS phosphorylation as an effective drug target [88].

With pharmacologic or transgenic interventions designed to increase eNOS activity, it will be important to assess possible effects on eNOS uncoupling because eNOS can serve not only as a source for $\mathrm{NO}$ but also as a source for $\mathrm{O}_{2}-$. For future studies, it will be crucial to use experimental models of human disease in intact animals that reflect these complexities of NO signaling. Better yet, to the extent possible, examination of responses in patients will yield the most clinically relevant and dependable information. Now that we understand the complex relationships between insulin resistance, visceral adiposity and endothelial dysfunction, the task before us is to translate this knowledge into effective treatments to reduce CVD, which is the leading cause of morbidity and mortality from diabetes and related metabolic diseases.

\section{References}

1. Reaven GM. Banting Lecture 1988. Role of insulin resistance in human disease. Diabetes 1988;37:1595-1607. [PubMed: 3056758]

2. Grundy SM. Metabolic syndrome: a multiplex cardiovascular risk factor. J. Clin. Endocrinol. Metab 2007;92:399-404. [PubMed: 17284640]

3. Grundy SM, et al. Diagnosis and management of the metabolic syndrome: an American Heart Association/National Heart, Lung, and Blood Institute scientific statement. Circulation 2005;112:2735-2752. [PubMed: 16157765]

4. National Cholesterol Education Program (NCEP) Expert Panel on Detection, Evaluation and Treatment of High Blood Cholesterol in Adults. Third Report of the National Cholesterol Education Program (NCEP) Expert Panel on Detection, Evaluation, and Treatment of High Blood Cholesterol in Adults (Adult Treatment Panel III) Final Report. Circulation 2002;106:3143-3421. [PubMed: 12485966]

5. Dandona P, et al. Metabolic syndrome: a comprehensive perspective based on interactions between obesity, diabetes, and inflammation. Circulation 2005;111:1448-1454. [PubMed: 15781756]

6. Paoletti R, et al. Metabolic syndrome, inflammation and atherosclerosis. Vasc. Health Risk Manag 2006;2:145-152. [PubMed: 17319458]

7. Alberti KG, Zimmet PZ. Definition, diagnosis and classification of diabetes mellitus and its complications. Part 1: diagnosis and classification of diabetes mellitus provisional report of a WHO consultation. Diabet. Med 1998;15:539-553. [PubMed: 9686693]

8. Balkau B, Charles MA. Comment on the provisional report from the WHO consultation. European Group for the Study of Insulin Resistance (EGIR). Diabet. Med 1999;16:442-443. [PubMed: 10342346]

9. Zimmet P, et al. The metabolic syndrome: a global public health problem and a new definition. J. Atheroscler. Thromb 2005;12:295-300. [PubMed: 16394610]

10. Kahn R, et al. The metabolic syndrome: time for a critical appraisal: joint statement from the American Diabetes Association and the European Association for the Study of Diabetes. Diabetes Care 2005;28:2289-2304. [PubMed: 16123508]

11. Reaven GM. The metabolic syndrome: is this diagnosis necessary? Am. J. Clin. Nutr 2006;83:12371247. [PubMed: 16762930] 
12. Dagogo-Jack S. Primary prevention of cardiovascular disease in pre-diabetes: the glass is half full and half empty. Diabetes Care 2005;28:971-972. [PubMed: 15793208]

13. Meigs JB. Metabolic syndrome: in search of a clinical role. Diabetes Care 2004;27:2761-2763. [PubMed: 15505020]

14. Kershaw EE, Flier JS. Adipose tissue as an endocrine organ. J. Clin. Endocrinol. Metab 2004;89:2548-2556. [PubMed: 15181022]

15. Gimbrone MA Jr, et al. Endothelial dysfunction, hemodynamic forces, and atherogenesis. Ann. N. Y. Acad. Sci 2000;902:230-239. [PubMed: 10865843]

16. Gimbrone MA Jr, et al. Vascular endothelium. An integrator of pathophysiological stimuli in atherogenesis. Ann. N. Y. Acad. Sci 1995;748:122-131. [PubMed: 7535025]

17. Ross R. Atherosclerosis is an inflammatory disease. Am. Heart J 1999;138:S419-S420. [PubMed: 10539839]

18. Steinberg D. The pathogenesis of atherosclerosis. An interpretive history of the cholesterol controversy, part iv: the 1984 coronary primary prevention trial ends it - almost. J. Lipid Res 2006;47:1-14. [PubMed: 16227628]

19. Alderton WK, et al. Nitric oxide synthases: structure, function and inhibition. Biochem. J 2001;357:593-615. [PubMed: 11463332]

20. Dudzinski DM, et al. The regulation and pharmacology of endothelial nitric oxide synthase. Annu. Rev. Pharmacol. Toxicol 2006;46:235-276. [PubMed: 16402905]

21. Gibbs WW, et al. The 1998 Nobel Prizes in Science. Sci. Am 1999;280:16-19.

22. Smith O. Nobel Prize for no research. Nat. Med 1998;4:1215. [PubMed: 9809526]

23. Huang PL, et al. Hypertension in mice lacking the gene for endothelial nitric oxide synthase. Nature 1995;377:239-242. [PubMed: 7545787]

24. Moroi M, et al. Interaction of genetic deficiency of endothelial nitric oxide, gender, and pregnancy in vascular response to injury in mice. J. Clin. Invest 1998;101:1225-1232. [PubMed: 9502763]

25. Lefer DJ, et al. Leukocyte-endothelial cell interactions in nitric oxide synthase-deficient mice. Am. J. Physiol 1999;276:H1943-H1950. [PubMed: 10362674]

26. Freedman JE, et al. Deficient platelet-derived nitric oxide and enhanced hemostasis in mice lacking the NOSIII gene. Circ. Res 1999;84:1416-1421. [PubMed: 10381894]

27. Chen J, et al. Hypertension does not account for the accelerated atherosclerosis and development of aneurysms in male apolipoprotein E/endothelial nitric oxide synthase double knockout mice. Circulation 2001;104:2391-2394. [PubMed: 11705813]

28. Kuhlencordt PJ, et al. Accelerated atherosclerosis, aortic aneurysm formation, and ischemic heart disease in apolipoprotein E/endothelial nitric oxide synthase double-knockout mice. Circulation 2001;104:448-454. [PubMed: 11468208]

29. Deanfield JE, et al. Endothelial function and dysfunction: testing and clinical relevance. Circulation 2007;115:1285-1295. [PubMed: 17353456]

30. Widlansky ME, et al. The clinical implications of endothelial dysfunction. J. Am. Coll. Cardiol 2003;42:1149-1160. [PubMed: 14522472]

31. Jonk AM, et al. Microvascular dysfunction in obesity: a potential mechanism in the pathogenesis of obesity-associated insulin resistance and hypertension. Physiology (Bethesda) 2007;22:252-260. [PubMed: 17699878]

32. Kim JA, et al. Reciprocal relationships between insulin resistance and endothelial dysfunction: molecular and pathophysiological mechanisms. Circulation 2006;113:1888-1904. [PubMed: 16618833]

33. Semenkovich CF. Insulin resistance and atherosclerosis. J. Clin. Invest 2006;116:1813-1822. [PubMed: 16823479]

34. Barton M. Endothelial dysfunction and atherosclerosis: endothelin receptor antagonists as novel therapeutics. Curr. Hypertens. Rep 2000;2:84-91. [PubMed: 10981133]

35. Cai H, Harrison DG. Endothelial dysfunction in cardiovascular diseases: the role of oxidant stress. Circ. Res 2000;87:840-844. [PubMed: 11073878]

36. Hink U, et al. Mechanisms underlying endothelial dysfunction in diabetes mellitus. Circ. Res 2001;88:E14-E22. [PubMed: 11157681] 
37. Corretti MC, et al. Guidelines for the ultrasound assessment of endothelial-dependent flow-mediated vasodilation of the brachial artery: a report of the International Brachial Artery Reactivity Task Force. J. Am. Coll. Cardiol 2002;39:257-265. [PubMed: 11788217]

38. Anderson TJ, et al. Close relation of endothelial function in the human coronary and peripheral circulations. J. Am. Coll. Cardiol 1995;26:1235-1241. [PubMed: 7594037]

39. Takase B, et al. Comparable prognostic value of vasodilator response to acetylcholine in brachial and coronary arteries for predicting long-term cardiovascular events in suspected coronary artery disease. Circ. J 2006;70:49-56. [PubMed: 16377924]

40. Huang PL. Unraveling the links between diabetes, obesity, and cardiovascular disease. Circ. Res 2005;96:1129-1131. [PubMed: 15947251]

41. Wang Y, Marsden PA. Nitric oxide synthases: gene structure and regulation. Adv. Pharmacol 1995;34:71-90. [PubMed: 8562454]

42. El-Sakka AI, et al. Effects of diabetes on nitric oxide synthase and growth factor genes and protein expression in an animal model. Int. J. Impot. Res 1999;11:123-132. [PubMed: 10404280]

43. Felaco M, et al. Endothelial nitric oxide synthase (eNOS) expression and localization in healthy and diabetic rat hearts. Ann. Clin. Lab. Sci 2001;31:179-186. [PubMed: 11337908]

44. Cooke JP. Does Adma cause endothelial dysfunction? Arterioscler. Thromb. Vasc. Biol 2000;20:2032-2037. [PubMed: 10978245]

45. Chen J, et al. Effects of chronic treatment with L-arginine on atherosclerosis in APOE knockout and APOE/inducible NO synthase double-knockout mice. Arterioscler. Thromb. Vasc. Biol 2003;23:97103. [PubMed: 12524231]

46. Cosentino F, et al. Tetrahydrobiopterin alters superoxide and nitric oxide release in prehypertensive rats. J. Clin. Invest 1998;101:1530-1537. [PubMed: 9525996]

47. Shaul PW. Regulation of endothelial nitric oxide synthase: location, location, location. Annu. Rev. Physiol 2002;64:749-774. [PubMed: 11826287]

48. Dimmeler $\mathrm{S}$, et al. Activation of nitric oxide synthase in endothelial cells by Akt-dependent phosphorylation. Nature 1999;399:601-605. [PubMed: 10376603]

49. Fulton D, et al. Regulation of endothelium-derived nitric oxide production by the protein kinase Akt. Nature 1999;399:597-601. [PubMed: 10376602]

50. Gallis B, et al. Identification of flow-dependent endothelial nitric-oxide synthase phosphorylation sites by mass spectrometry and regulation of phosphorylation and nitric oxide production by the phosphatidylinositol 3-kinase inhibitor Ly294002. J. Biol. Chem 1999;274:30101-30108. [PubMed: 10514497]

51. Michell BJ, et al. The Akt kinase signals directly to endothelial nitric oxide synthase. Curr. Biol 1999;9:945-948.

52. Pacher P, et al. Nitric oxide and peroxynitrite in health and disease. Physiol. Rev 2007;87:315-424. [PubMed: 17237348]

53. Griendling KK, et al. Modulation of protein kinase activity and gene expression by reactive oxygen species and their role in vascular physiology and pathophysiology. Arterioscler. Thromb. Vasc. Biol 2000;20:2175-2183. [PubMed: 11031201]

54. Nystrom FH, Quon MJ. Insulin signalling: metabolic pathways and mechanisms for specificity. Cell. Signal 1999;11:563-574. [PubMed: 10433517]

55. Saltiel AR, Kahn CR. Insulin signalling and the regulation of glucose and lipid metabolism. Nature 2001;414:799-806. [PubMed: 11742412]

56. Cusi K, et al. Insulin resistance differentially affects the PI3-kinase- and map kinase-mediated signaling in human muscle. J. Clin. Invest 2000;105:311-320. [PubMed: 10675357]

57. Jiang ZY, et al. Characterization of selective resistance to insulin signaling in the vasculature of obese Zucker ( $f a / f a$ ) rats. J. Clin. Invest 1999;104:447-457. [PubMed: 10449437]

58. Berg AH, Scherer PE. Adipose tissue, inflammation, and cardiovascular disease. Circ. Res 2005;96:939-949. [PubMed: 15890981]

59. Katagiri $\mathrm{H}$, et al. Adiposity and cardiovascular disorders: disturbance of the regulatory system consisting of humoral and neuronal signals. Circ. Res 2007;101:27-39. [PubMed: 17615379] 
60. Serne EH, et al. Microvascular dysfunction: apotential pathophysiological role in the metabolic syndrome. Hypertension 2007;50:204-211. [PubMed: 17470716]

61. Beckman JS, Koppenol WH. Nitric oxide, superoxide, and peroxynitrite: the good, the bad, and ugly. Am. J. Physiol 1996;271:C1424-C1437. [PubMed: 8944624]

62. Boo YC, Jo H. Flow-dependent regulation of endothelial nitric oxide synthase: role of protein kinases. Am. J. Physiol. Cell Physiol 2003;285:C499-C508. [PubMed: 12900384]

63. McCabe TJ, et al. Enhanced electron flux and reduced calmodulin dissociation may explain 'calciumindependent' eNOS activation by phosphorylation. J. Biol. Chem 2000;275:6123-6128. [PubMed: 10692402]

64. Kobayashi T, et al. Impairment of Pi3-K/Akt pathway underlies attenuated endothelial function in aorta of type 2 diabetic mouse model. Hypertension 2004;44:956-962. [PubMed: 15505117]

65. Naoum JJ, et al. Aortic eNOS expression and phosphorylation in APO-E knockout mice: differing effects of rapamycin and simvastatin. Surgery 2004;136:323-328. [PubMed: 15300198]

66. Hisamoto K, et al. Estrogen induces the Akt-dependent activation of endothelial nitric-oxide synthase in vascular endothelial cells. J. Biol. Chem 2001;276:3459-3467. [PubMed: 11044445]

67. Kureishi Y, et al. The HMG-CoA reductase inhibitor simvastatin activates the protein kinase Akt and promotes angiogenesis in normocholesterolemic animals. Nat. Med 2000;6:1004-1010. [PubMed: 10973320]

68. Cho DH, et al. Nitric oxide production and regulation of endothelial nitric-oxide synthase phosphorylation by prolonged treatment with troglitazone: evidence for involvement of peroxisome proliferator-activated receptor (PPAR) gamma-dependent and PPAR gamma-independent signaling pathways. J. Biol. Chem 2004;279:2499-2506. [PubMed: 14593122]

69. Wang Y, et al. Effects of bezafibrate on the expression of endothelial nitric oxide synthase gene and its mechanisms in cultured bovine endothelial cells. Atherosclerosis 2006;187:265-273. [PubMed: 16256120]

70. Chen ZP, et al. Amp-activated protein kinase phosphorylation of endothelial NO synthase. FEBS Lett 1999;443:285-289. [PubMed: 10025949]

71. Montagnani M, et al. Insulin-stimulated activation of eNOS is independent of $\mathrm{Ca} 2+$ but requires phosphorylation by Akt at ser1179. J. Biol. Chem 2001;276:30392-30398. [PubMed: 11402048]

72. Vecchione $\mathrm{C}$, et al. Leptin effect on endothelial nitric oxide is mediated through Akt-endothelial nitric oxide synthase phosphorylation pathway. Diabetes 2002;51:168-173. [PubMed: 11756337]

73. Boo YC, et al. Shear stress stimulates phosphorylation of endothelial nitric-oxide synthase at Ser1179 by Akt-independent mechanisms: role of protein kinase A. J. Biol. Chem 2002;277:3388-3396. [PubMed: 11729190]

74. Butt E, et al. Endothelial nitric-oxide synthase (type III) is activated and becomes calcium independent upon phosphorylation by cyclic nucleotide-dependent protein kinases. J. Biol. Chem 2000;275:5179_ 5187. [PubMed: 10671564]

75. Cai H, et al. Cam kinase II-dependent pathophysiological signalling in endothelial cells. Cardiovasc. Res 2008;77:30-34. [PubMed: 18006482]

76. Scotland RS, et al. Functional reconstitution of endothelial nitric oxide synthase reveals the importance of serine 1179 in endothelium-dependent vasomotion. Circ. Res 2002;90:904-910. [PubMed: 11988492]

77. Chen $\mathrm{H}$, et al. Adiponectin stimulates production of nitric oxide in vascular endothelial cells. J. Biol. Chem 2003;278:45021-45026. [PubMed: 12944390]

78. Meier U, Gressner AM. Endocrine regulation of energy metabolism: review of pathobiochemical and clinical chemical aspects of leptin, ghrelin, adiponectin, and resistin. Clin. Chem 2004;50:15111525. [PubMed: 15265818]

79. Green A, et al. Tumor necrosis factor increases the rate of lipolysis in primary cultures of adipocytes without altering levels of hormone-sensitive lipase. Endocrinology 1994;134:2581-2588. [PubMed: 8194485]

80. Beltowski J, et al. Leptin decreases plasma paraoxonase 1 (PON1) activity and induces oxidative stress: the possible novel mechanism for proatherogenic effect of chronic hyperleptinemia. Atherosclerosis 2003;170:21-29. [PubMed: 12957679] 
81. Vicent $\mathrm{D}$, et al. The role of endothelial insulin signaling in the regulation of vascular tone and insulin resistance. J. Clin. Invest 2003;111:1373-1380. [PubMed: 12727929]

82. Erusalimsky JD, Moncada S. Nitric oxide and mitochondrial signaling: from physiology to pathophysiology. Arterioscler. Thromb. Vasc. Biol 2007;27:2524-2531. [PubMed: 17885213]

83. Nisoli E, et al. Defective mitochondrial biogenesis: a hallmark of the high cardiovascular risk in the metabolic syndrome? Circ. Res 2007;100:795-806. [PubMed: 17395885]

84. Clementi E, Nisoli E. Nitric oxide and mitochondrial biogenesis: a key to long-term regulation of cellular metabolism. Comp. Biochem. Physiol. A Mol. Integr. Physiol 2005;142:102-110. [PubMed: 16091305]

85. Nisoli E, Carruba MO. Nitric oxide and mitochondrial biogenesis. J. Cell Sci 2006;119:2855-2862. [PubMed: 16825426]

86. Nisoli E, et al. Mitochondrial biogenesis in mammals: the role of endogenous nitric oxide. Science 2003;299:896-899. [PubMed: 12574632]

87. Nisoli E, et al. Calorie restriction promotes mitochondrial biogenesis by inducing the expression of eNOS. Science 2005;310:314-317. [PubMed: 16224023]

88. Atochin DN, et al. The phosphorylation state of eNOS modulates vascular reactivity and outcome of cerebral ischemia in vivo. J. Clin. Invest 2007;117:1961-1967. [PubMed: 17557122] 


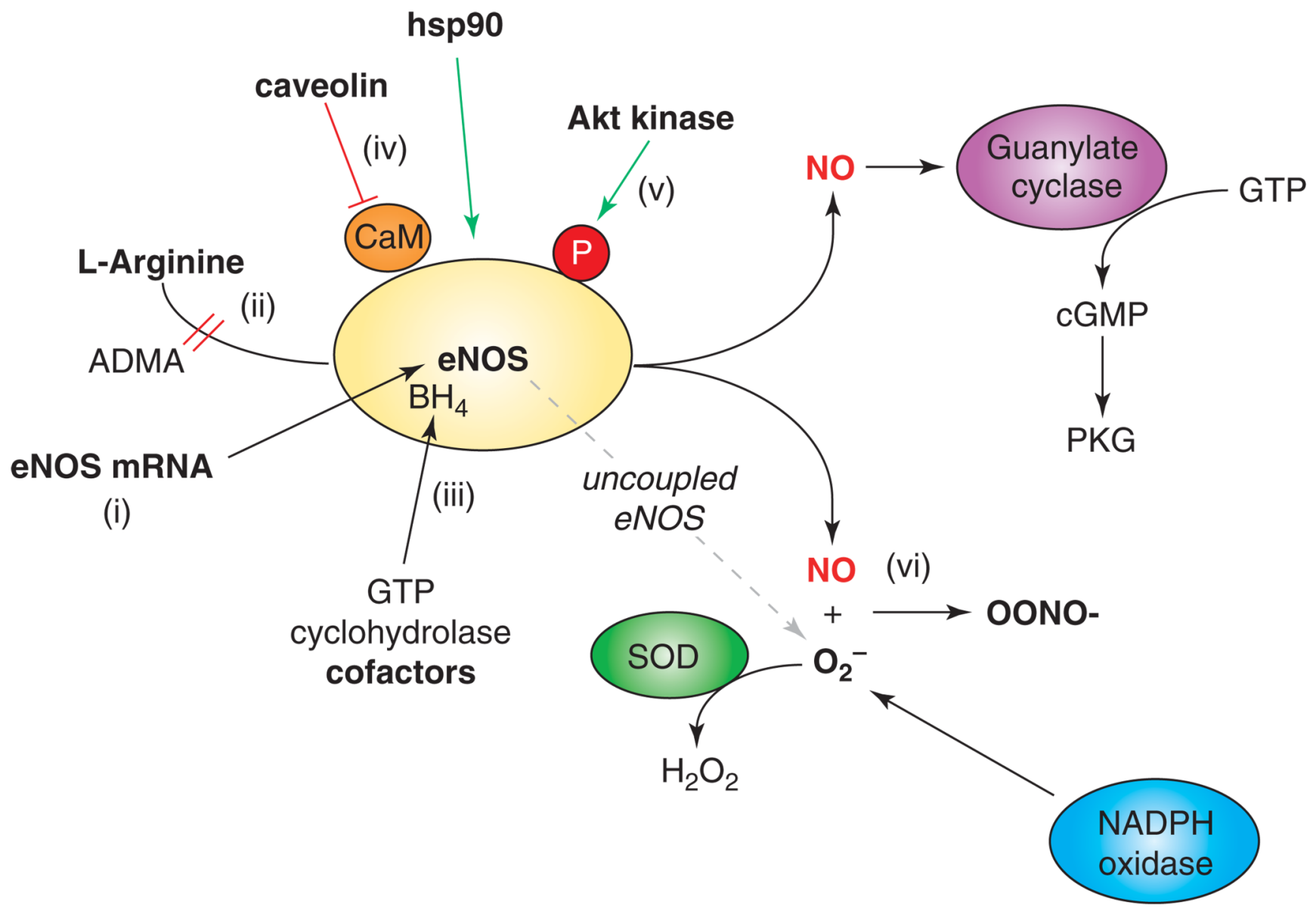

TRENDS in Endocrinology \& Metabolism

Figure 1.

Regulation of eNOS activity and mechanisms of endothelial dysfunction. The bioavailability of NO produced by eNOS might be affected at multiple levels, including (i) eNOS mRNA or protein expression; (ii) availability of L-arginine, its substrate, which might be competed by ADMA; (iii) availability of its cofactors, including BH4, for which GTP cyclohydrolase catalyzes the rate-limiting step; (iv) protein-protein interactions, for example with caveolin (inhibitory; red) or hsp90 (stimulatory; green); (v) post-translational modifications, such as phosphorylation at S1177 by Akt and other kinases (stimulatory; green); and (vi) reaction of NO with superoxide to yield peroxynitrite anion. Abbreviations: ADMA, asymmetric dimethyl arginine; $\mathrm{BH} 4$, tetrahydrobiopterin; eNOS, endothelial nitric oxide synthase; GTP, guanosine $5^{\prime}$-triphosphate; hsp90, heat-shock protein 90; $\mathrm{NO}$, nitric oxide; $\mathrm{O}_{2}^{-}$, superoxide; $\mathrm{OONO}^{-}$, peroxynitrite anion; PKG, protein kinase G; SOD, superoxide dismutase. 


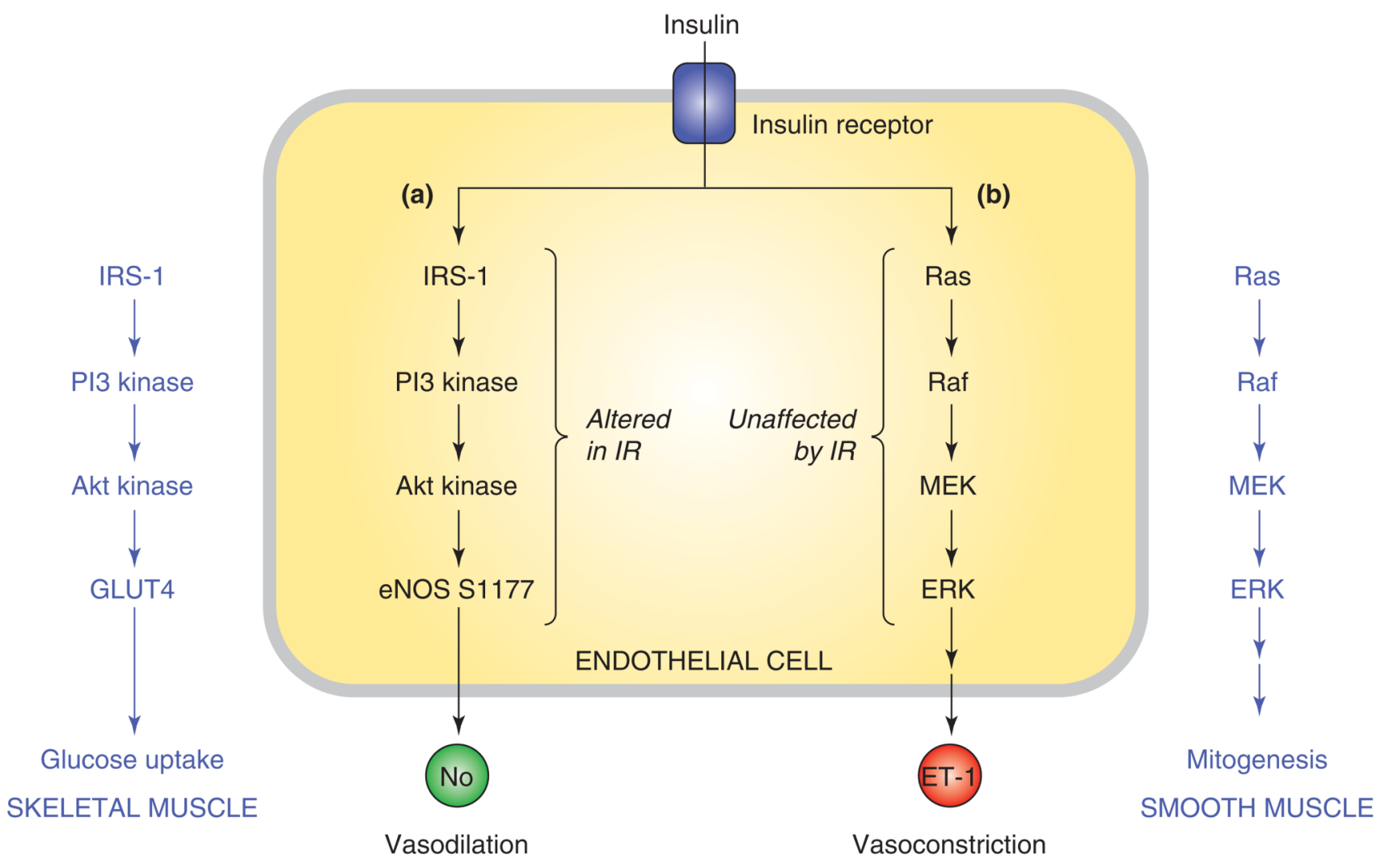

TRENDS in Endocrinology \& Metabolism

Figure 2.

Insulin signaling. Insulin signaling in endothelial cells occurs after insulin binding to the insulin receptor. This causes activation of two separate and parallel pathways: (i) PI3K-Akt and (ii) Ras/Raf/MAP kinase. (i) Akt kinase phosphorylates eNOS at S1177, resulting in increased NO production and vasodilation. (ii) The MAP kinase pathway results in endothelin-1 production and vasoconstriction. In other tissues, these pathways have effects (shown in dark blue lettering). In skeletal muscle (left), the PI3K-Akt pathway results in translocation of GLUT4 and glucose uptake. In vascular smooth muscle (right), the MAP kinase pathway results in growth and mitogenesis. Abbreviations: eNOS, endothelial nitric oxide synthase; ET-1, endothelin-1; GLUT4, insulin-dependent glucose transporter 4'; MAP kinase, mitogenactivated protein kinase; PI3K, phosphatidylinositol-3-kinase. 

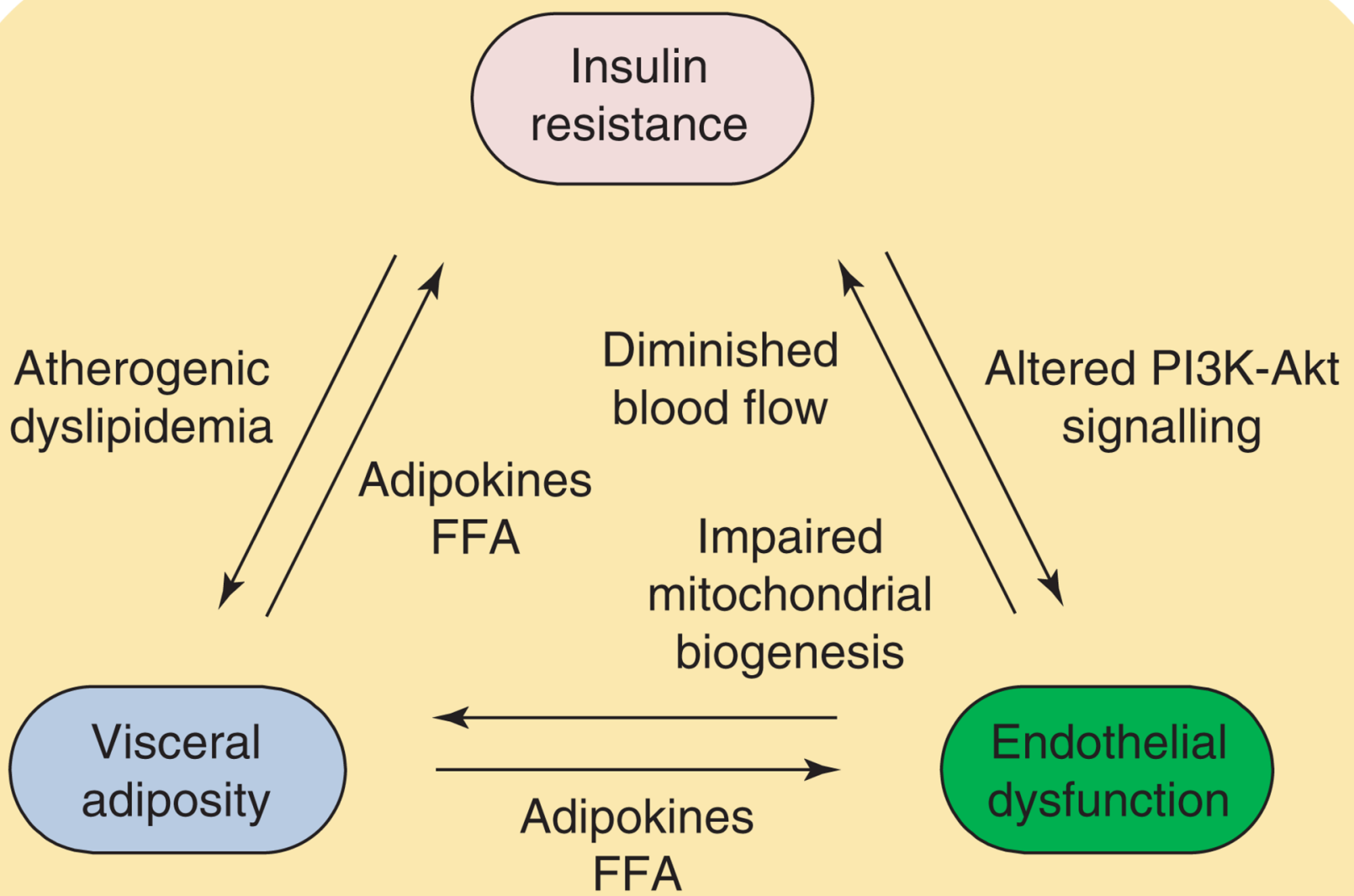

TRENDS in Endocrinology \& Metabolism

Figure 3.

Relationships between insulin resistance, visceral adiposity, and endothelial dysfunction. Insulin 3 resistance can cause endothelial dysfunction through altered PI3K-Akt signaling. Endothelial dysfunction, in turn, can cause insulin resistance owing to diminished blood flow and capillary recruitment, leading to decreased substrate and insulin delivery. Endothelial dysfunction can lead to insulin resistance, as well as visceral adiposity by impaired mitochondrial biogenesis. Visceral adipose tissue can secrete adipokines and FFAs, which can cause endothelial dysfunction and peripheral insulin resistance. Finally, insulin resistance can lead to atherogenic dyslipidemia, which can contribute to visceral obesity. Abbreviations: PI3K, phosphatidylinositol-3-kinase; FFAs, free fatty acids. 


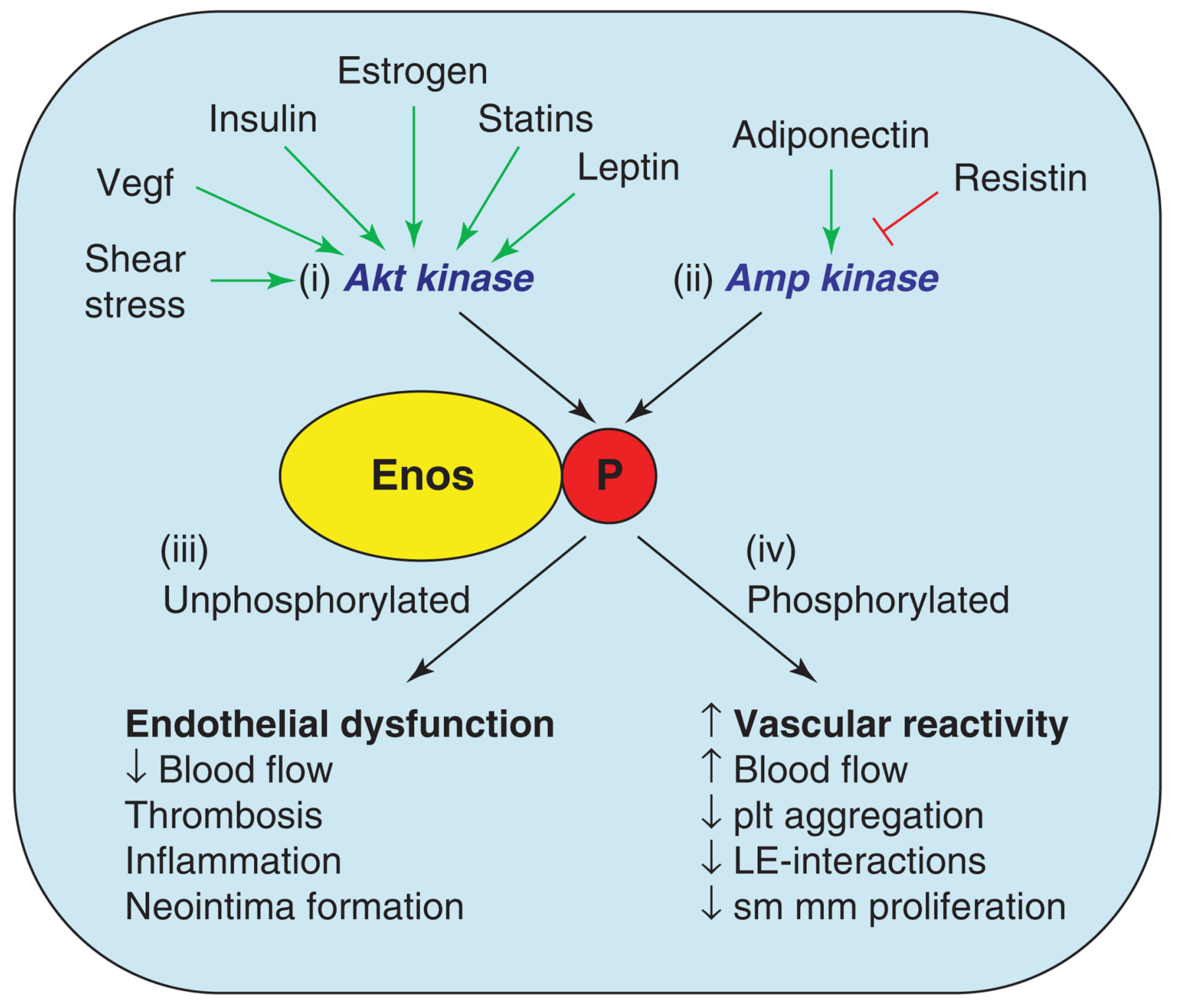

TRENDS in Endocrinology \& Metabolism

Figure 4.

Role of eNOS S1177 phosphorylation in integrating effects of multiple mediators. eNOS S1177 is phosphorylated by multiple kinases, including (i) Akt kinase and (ii) AMP kinase. Shear stress, VEGF, insulin, estrogen, statins and leptin all act through Akt kinase to increase S1177 phosphorylation. Adiponectin, resistin and other metabolic signals act through AMP kinase to influence S1177 phosphorylation. (iii) The S1177 unphosphorylated form of eNOS has less enzymatic activity and is associated with lower vascular NO levels than the phosphorylated form. (iv) By contrast, S1177 phosphorylated eNOS is associated with increased vascular reactivity, higher vascular NO levels, and protective effects on vascular smooth muscle proliferation, leukocyte-endothelial interactions and platelet aggregation. Abbreviations: AMP, adenosine monophosphate; eNOS, endothelial nitric oxide synthase; LE, leukocyteendothelial; plt, platelet; VEGF, vascular endothelial growth factor. The green arrows indicate 
stimulation of eNOS S1177 phosphorylation, and the red inhibitory signal indicates inhibition of S1177 phosphorylation by resistin. 
Definitions of metabolic syndrome

Table 1

\begin{tabular}{|c|c|c|c|c|}
\hline & $\begin{array}{l}\text { NCEP ATP III ( } 2005 \\
\text { revision) }\end{array}$ & WHO (1999) & EGIR (1999) & IDF (2005) \\
\hline Absolutely required & None & $\begin{array}{l}\text { Insulin resistance }{ }^{a} \text { (IGT, IFG, } \\
\text { T2D, or other evidence of IR) }\end{array}$ & $\begin{array}{l}\text { Hyperinsulinemia } \\
\text { insulin }>75^{\text {th }} \text { percentile) }\end{array}$ & $\begin{array}{l}\text { Central obesity: waist } \\
\text { circumference }{ }^{d} \geq 94 \mathrm{~cm}(\mathrm{M}) \\
\text { or } \geq 80 \mathrm{~cm}(\mathrm{~F})\end{array}$ \\
\hline Criteria & $\begin{array}{l}\text { Any three of five criteria } \\
\text { below }\end{array}$ & $\begin{array}{l}\text { Insulin resistance or diabetes, } \\
\text { plus two of five criteria below }\end{array}$ & $\begin{array}{l}\text { Hyperinsulinemia, plus two of } \\
\text { four criteria below }\end{array}$ & $\begin{array}{l}\text { Obesity, plus two of four } \\
\text { criteria below }\end{array}$ \\
\hline Obesity & $\begin{array}{l}\text { Waist circumference }>40 \\
\text { inches }(M) \text { or }>35 \text { inches }(F)\end{array}$ & $\begin{array}{l}\text { Waist/hip ratio }>0.90(\mathrm{M}) \text { or } \\
>0.85(\mathrm{~F}) \text {, or } \mathrm{BMI}>30 \mathrm{~kg} / \mathrm{m} 2\end{array}$ & $\begin{array}{l}\text { Waist circumference } \geq 94 \mathrm{~cm} \\
(\mathrm{M}) \text { or } \geq 80 \mathrm{~cm}(\mathrm{~F})\end{array}$ & $\begin{array}{l}\text { Central obesity already } \\
\text { required }\end{array}$ \\
\hline Hyperglycemia & $\begin{array}{l}\text { Fasting glucose } \geq 100 \mathrm{mg} / \mathrm{dl} \\
\text { or } \mathrm{Rx}\end{array}$ & $\begin{array}{l}\text { Insulin resistance already } \\
\text { required }\end{array}$ & $\begin{array}{l}\text { Insulin resistance already } \\
\text { required }\end{array}$ & Fasting glucose $\geq 100 \mathrm{mg} / \mathrm{dl}$ \\
\hline Dyslipidemia & $\mathrm{TG} \geq 150 \mathrm{mg} / \mathrm{dl}$ or $\mathrm{Rx}$ & $\begin{array}{l}\mathrm{TG} \geq 150 \mathrm{mg} / \mathrm{dl}, \text { or HDL-C } \\
<35 \mathrm{mg} / \mathrm{dl}(\mathrm{M}) \text { or }<39 \mathrm{mg} / \mathrm{dl}(\mathrm{F})\end{array}$ & $\begin{array}{l}\mathrm{TG} \geq 177 \mathrm{mg} / \mathrm{dl} \text { or HDL-C } \\
<39 \mathrm{mg} / \mathrm{dl}\end{array}$ & $\mathrm{TG} \geq 150 \mathrm{mg} / \mathrm{dl}$ or $\mathrm{Rx}$ \\
\hline $\begin{array}{l}\text { Dyslipidemia (second, } \\
\text { separate criteria) }\end{array}$ & $\begin{array}{l}\text { HDL cholesterol }<40 \mathrm{mg} / \mathrm{dl} \\
(\mathrm{M}) \text { or }<50 \mathrm{mg} / \mathrm{dl}(\mathrm{F}), \text { or } \mathrm{Rx}\end{array}$ & & & $\begin{array}{l}\text { HDL cholesterol }<40 \mathrm{mg} / \mathrm{dl} \\
\text { (M) or }<50 \mathrm{mg} / \mathrm{dl}(\mathrm{F}) \text {, or Rx }\end{array}$ \\
\hline Hypertension & $\begin{array}{l}>130 \mathrm{mmHg} \text { systolic or } \\
>85 \mathrm{mmHg} \text { diastolic, or } \mathrm{Rx}\end{array}$ & $\geq 140 / 90 \mathrm{mmHg}$ & $\geq 140 / 90 \mathrm{mmHg}$ or $\mathrm{Rx}$ & $\begin{array}{l}>130 \mathrm{mmHg} \text { systolic or } \\
>85 \mathrm{mmHg} \text { diastolic, or } \mathrm{Rx}\end{array}$ \\
\hline Other criteria & & Microalbuminuria $^{b}$ & & \\
\hline Refs & {$[3,4]$} & [7] & [8] & [9] \\
\hline
\end{tabular}

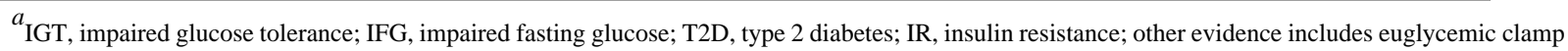
studies.

${ }^{b}$ Urinary albumin excretion $\geq 20 \mu \mathrm{g} / \mathrm{min}$ or albumin-to-creatinine ratio $\geq 30 \mathrm{mg} / \mathrm{g}$.

${ }^{c}$ Reliable only in patients without T2D.

${ }^{d}$ Criteria for central obesity (waist circumference) are specific for each population; values given are for European men and women. 
Table 2

NOS isoforms

\begin{tabular}{|c|c|c|c|}
\hline & Type 1 NOS & Type 2 NOS & Type 3 NOS \\
\hline Common name & nNOS & iNOS & eNOS \\
\hline Cell type & Neurons & Macrophages & Endothelium \\
\hline Chromosome & 12 & 17 & 7 \\
\hline Expression pattern & Constitutive & Inducible & Constitutive \\
\hline Intracellular location & Soluble, sarcolemma & Soluble & Caveolae (membrane-associated) \\
\hline Localization & $\mathrm{N}$-terminal PDZ domain & N/A & $\mathrm{N}$-terminal myristoylation \\
\hline Regulation & Calcium-CaM & Transcription & $\begin{array}{l}\text { Calcium-CaM } \\
\text { Phosphorylation }\end{array}$ \\
\hline Output & Moderate (nM to $\mu \mathrm{M}$ ) & $\operatorname{High}(\mu \mathrm{M})$ & Low (pM to $\mathrm{nM}$ ) \\
\hline Function & Signaling & Toxin & Signaling \\
\hline Biological processes & $\begin{array}{l}\text { Learning/memory } \\
\text { Neurotransmission } \\
\text { Autonomic functions }\end{array}$ & $\begin{array}{l}\text { Inflammation } \\
\text { Immune defense }\end{array}$ & $\begin{array}{l}\text { Vasodilation } \\
\text { Cell proliferation } \\
\text { Leukocyte adhesion } \\
\text { Thrombosis }\end{array}$ \\
\hline Phenotype of knockout mice & $\begin{array}{l}\text { Normal central nervous system } \\
\text { development } \\
\text { Pyloric stenosis } \\
\text { Resistance to stroke }\end{array}$ & $\begin{array}{l}\text { Susceptibility to infections } \\
\text { Resistance to septic hypotension }\end{array}$ & $\begin{array}{l}\text { Absence of EDRF } \\
\text { Hypertension } \\
\text { Increased vascular response to injury } \\
\text { Increased atherosclerosis }\end{array}$ \\
\hline
\end{tabular}

